\title{
Study on slope risk level of Hydropower Engineering
}

\author{
LI Bin ${ }^{123, a}$, LIU Xin ${ }^{123}$ \\ ${ }^{1}$ Tianjin Port Engineering Institute Ltd. of CCCC First Harbor Engineering Company Ltd., Tianjin, \\ 30222 China; \\ ${ }^{2}$ Key laboratory of port geotechnical engineering, ministry of communications, PRC Tianjin, 30222 \\ China; \\ ${ }^{3}$ Key laboratory of port geotechnical engineering of Tianjin, Tianjin, 30222 China; \\ aemail:lee_binbin@163.com
}

Key words: slope; ratio safety margin; risk standard; safety factor;

Abstract: The slope of hydropower engineering belong to which kind of risk level should be verified. Summarized the research results of safety standards and failure probability about slope, proposed slope acceptable risk criteria (failure probability), computed safety factor and failure probability, reliability method of ratio safety margin is used to vindicated rationality of slope stability risk standard, and the results show that the safety factor of slope stability 1.3 and reliability index 3.7 at the same level of risk control. The safety factor of the normal slope 1.3 meet the actual engineering needs, but the stability safety factor of the important high slope project should be improved.

\section{Introduction}

With the improvement of dam construction technology, dam height is higher than $200 \mathrm{~m}$, such as nozhadu, shuibuya and shuangjiangkou, those hydropower engineering have been construction or operation. The high slope stability of import and export of drainage structures concern engineering safety. The safety factor of slope with high risk determined by specification of earth dam design and construction whether it is appropriate should be solved, put forward reasonable safety factor of high slope stability of extra height dam is the urgent need of reality.

Before putting forward high slope safety standards, slope safety factor and reliability index should be analyzed, improve the evaluation methods of slope safety.

This article begin from the safety factor and reliability index of the current slope reliability standards, research on failure probability in our country and abroad in recent years, put forward a risk acceptable failure probability of slope, and evaluate the stability safety factor and reliability index of slope, which lay a foundation for the safety standards of high slope.

\section{risk control standard of slope}

The extra height dams are constructing, the problem of security and stability of high slope is coming with it. The slope specification of Water conservancy and hydropower stipulated safety level of slope according to the level of the hydraulic structures to determinate, but a first-class engineering safety standard is unlimited, so slope safety standards of high dam which influence the safe of the engineering follow the first-class engineering standard to design safety slope is not reasonable. Another, the current slope design specification of the earth dam is not a widely accepted allowed reliable indicator. In this paper, from the viewpoint of statistics and engineering safety, on the slope failure probability are discussed. 
In the field of engineering risk analysis and risk management, allowed risk standard usually is described as a probability that the life of person will be destroyed in every single year. This is an easy operation description of risk index. In China there is no clear slope risk standard, the overseas related research started early, more mature. Risk figure related materials of other countries and regions slope are collected, on the basis of this information to research slope risk control standard of China.

According to the ministry of land and resources issued in $2004 \sim 2013$ national geological disasters, according to the landslide disaster of geological disasters by the proportion of the total number of casualties calculated landslide casualties every year in our country, the significant individual landslide disasters have the detailed record need separate statistics. Roughly counted casualties in this decade caused by landslide disaster, statistical data as shown in table 1.

Table 1 China's annual landslide disaster casualties' statistical table

\begin{tabular}{ccc}
\hline year & casualties & risk $\left(10^{-5}\right)$ \\
\hline 2004 & 735 & 0.2 \\
2005 & 486 & 0.6 \\
2006 & 970 & 1.0 \\
2007 & 635 & 0.3 \\
2008 & 757 & 0.2 \\
2009 & 394 & 0.6 \\
2010 & 647 & 0.6 \\
2011 & 302 & 0.8 \\
2012 & 380 & 0.8 \\
2013 & 476 & 0.6 \\
\hline
\end{tabular}

From table 1 can be seen, nearly 10 years in China, the landslide disaster caused casualties every year is about $400 \sim 1000$, through a risk figure access to the risk of slope in $10^{-5} \sim 10^{-6}$. International risk analysis of slope expert professor Fell, through analysis of the risk of various industries, for passive risk-drivers, allowed risk should be less than $10^{-6}$ in annual terms, no larger than $10^{-5}$. For the slope engineering, Fell on the detailed review and analysis of the risk of slope in theory and practice experience, put forward as shown in table 2 control standards.

Table 2 Professor Fell advises slope risk analysis control standards

\begin{tabular}{ll}
\hline situation & allowed risk in annual \\
\hline \multirow{2}{*}{ Established slope } & $10^{-4}$, the nearby people \\
& $10^{-6}$, the general population \\
\cline { 2 - 2 } New slope & $10^{-5}$, The nearby people \\
& $10^{-6}$, the general population \\
\hline
\end{tabular}

Risk criteria and location of slope region also has a certain relationship with the level of economic development, through the statistics, in general, different countries and regions have the probability of death all around $10^{-6}$ caused by disasters, as shown in table 3 . 
Table 3 Recent years, the average number of deaths and the annual probability of countries

\begin{tabular}{lccc}
\hline \multicolumn{1}{c}{ country } & $\begin{array}{c}\text { annual } \\
\text { death }\end{array}$ & $\begin{array}{c}\text { toll } \\
\text { population }\end{array}$ & landslide in personnel death probability \\
\hline Japan & 150 & 150000000 & $1 / 1 \times 10^{-6}$ \\
South Korea & 56 & 70000000 & $1 / 1 \times 10^{-6}$ \\
The United States & $25 \sim 50$ & 250000000 & $1 / 1 \sim 2 \times 10^{-6}$ \\
Australia & $<1$ & 17000000 & $1 / 17 \times 10^{-6}$ \\
Canada & 5 & 30000000 & $1 / 6 \times 10^{-6}$ \\
Hong Kong $(1984 \sim 1984)$ & 1 & 5800000 & $1 / 6 \times 10^{-6}$ \\
\hline
\end{tabular}

According to the analysis of slope of countries and regions, reference to risk standard of some foreign countries and China's economic development level, for the natural slope and slope of China water resources and hydropower engineering, put forward the acceptable risk of slope in China should be set as the failure probability in annual between $10^{-5} \sim 10^{-6}$. For the slope of the importance, the bigger, and the influence after the destruction, set the level of the failure probability of slope in annual terms as 10-6 can be widely accepted.

Chen zuyu suggested that the risk calculated by one year as Py and risk calculated by many years as $\mathrm{P}$ have the following relations.

$$
P \mathrm{y}=\frac{P}{T} \times \frac{N_{\mathrm{d}}}{T}
$$

The $\mathrm{T}$ for the life, Nd to design a base year.

Calculation follow as (1), often difficult to determine the life of a slope, as a conservative approach, assumes that $\mathrm{T}=\mathrm{Nd}$, the type can be expressed as:

$$
P_{\mathrm{y}}=\frac{P}{N_{\mathrm{d}}}
$$

In water resources and hydropower engineering, the design base year for 100 of first-class, the slope failure probability can be calculated for $10^{-4}$ by type (2), looking up the failure probability and reliability index table, the level of the slope reliability index is 3.7.

\section{risk standard calculation of slope}

China Institute of Water Conservancy and Hydropower institute proposed ratio safety margin method which is a measure between the safety standards and the design requirements of the building standard. Defined safety factor method of ratio safety margin $\quad \eta_{R}$ and traditional methods ratio safety margin $\eta_{F}$ are calculated as follows:

$$
\begin{array}{r}
\eta_{R}=\left(\beta-\beta_{a}\right) \sigma_{F}+1 \\
\eta_{F}=\frac{F}{F_{a}}
\end{array}
$$

Under the provision of the reasonable safety factor $F_{a}$ premise, reliability Methods of the ratio safety margin $\eta_{R}$ has a better ability to insinuate $\eta_{F}$.under any condition, can get $\eta_{R} \approx \eta_{F}$. So, it 
should be known that $F$ and $\beta$ at same risk control level which can be used as important theoretical references for preparation of specification working.

Factor safety standard of slope stability with extra height, which be determined by fitting coefficient of ratio safety margin. Calculate ratio safety margin of songta, nuozhadu and jingping hydropower station dam spillway slope with safety factor 1.3 and reliability index 3.7 , respectively different section forms to calculate the ratio safety margin with safety factor method and reliability method, and linear regression, if fitting slope approximation is 1, safety factor 1.3 and reliability index 3.7 at the same level of risk control. the calculation results linear regression results as shown in figure 1.

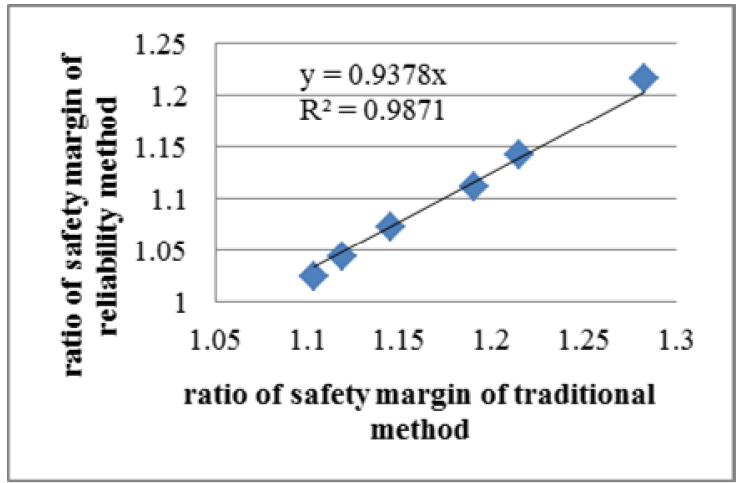

Fig. 1 hydropower station slope $\eta_{R^{-}} \eta_{F}$ correlation diagram

According to the result of linear regression shows that calculation results of three engineering slope fitting line slope is $1, \eta_{R^{-}} \eta_{F}$ correlation coefficient is close to 1 . That slope engineering results shown that slope safety factor standard 1.3 and reliability index 1.3 have the same safety margin; in the specification, reliability index 3.7 and safety factor 1.3 of grade I slope at the same level of risk control; grade I slope reliability index 3.7 is reasonable.

\section{conclusion}

Based on the ratio safety margin method, The $\eta_{R^{-}} \eta_{F}$ correlation diagram of hydropower station slope shown that the safety factor 1.3 and allowed reliability index 3.7 at the same risk level.

Three actual engineering calculations shown that the slope stability safety factor 1.3 meet the grade I slope engineering requirements. The method of safety standards determining of important high slope can considerate failure probability and safety factor from risk aspect.

\section{Reference:}

[1] Specification for design of rolled earth rock dam.(DL/T5395-2007) Beijing : China Electric Power Press, 2009

[2] Specification for design of rolled earth rock dam.(SL274-2001) Beijing : China Water Power press, 2002

[3] USNRC. Safety Goals for the Operation of Nuclear Power Plants. Federal Register, 1982, 47: 7023.

[4] CHEN Zu-yu. Soil slope stability analysis - Principles and methods [M], Beijing China Water Power press, 2003:181-196

[5] CHEN Zu-yu, CHEN Li-hong, Sun Ping. An investigation on the allowable factors of safety in slope stability analysis using nonlinear strength parameters[J] . Hydropower, 2004, 30(2): 17-20.

[6] CHEN Li-hong, CHEN Zu-yu. Influence of nonlinear strength characteristics of rockfill on the stability of high earth rockfill dam[J]. Rock and soil mechanics, 2007, 28(9): 1807-1810. 
[7] CHEN Zu-yu, XU Jia-cheng, SUN Ping, gravity sliding stability reliability analysis: (一) the relative safety factor method [J],Journal of Hydroelectric Engineering, 2012,1(3) :167-178

[8] CHEN Zu-yu, XU Jia-cheng, SUN Ping equality, dam stability against sliding reliability analysis: a reasonable value (II) Strength Index and sub-factors [J], Journal of Hydroelectric Engineering, 2012,31 (3): 160 -1167

[9] Specification for design of water conservancy and Hydropower Engineering Slope (SL386-2007) , Beijing: China Water Power press,2007

[10]Unified standard for reliability design of water conservancy and hydropower engineering structure （GB50199-1994）,Beijing: China Planning Press, 1994. 